\title{
Research on the System of Down-hole Engineering Parameters Measure While Drilling
}

\author{
Hu Ze ${ }^{1, *}$, Xie Xiaohui ${ }^{1}$, Ge Liang ${ }^{1}$, Chen Ping ${ }^{2}$, Li Junlan ${ }^{3}$ and Zeng Qiang ${ }^{1}$ \\ ${ }^{I}$ Southwest Petroleum University, Chengdu, 610000, P.R. China \\ ${ }^{2}$ State Key Laboratory of Oil and Gas Reservoir Geology and Exploitation, Chengdu, 610000, P.R. China \\ ${ }^{3}$ Southwest Branch, Engineering Design Co., CNPC, Chengdu, 610000, P.R. China
}

\begin{abstract}
The down-hole engineering parameters measure while drilling system is an important vehicle to monitor the down-hole parameters in the drilling process. By adopting it, the drilling engineer can grasp the engineering parameters of annulus pressure, drilling pressure, torque, temperature and so on. In real-time way, it can be used to learn and analyze the state of down-hole. The down-hole engineering parameters measure while drilling system adopts the Infineon XC886 MCU as the core chip, and uses the high reliability technology to complete the engineering parameters measuring dual system. The down-hole engineering parameters measure while drilling system has advantages of small size, low power consumption, vibration resistance and high temperature flexibility. Once the overall system is completed, to realize its engineering application, laboratory test, high temperature test, vibration test and spot test are made to check the function and the reliability of the system, and the field data in the spot test are successfully obtained.
\end{abstract}

Keywords: Data acquisition, Drilling engineering, Down-hole, Lithium battery, Vibration.

\section{INTRODUCTION}

Nowadays, some achievements have been made in the down-hole engineering parameters measure while drilling system in China. Currently oil and gas exploration is heading to the deeper layer of higher temperature and harsher environment $[1,2]$, The high temperature, strong vibration, high pressure as well as strong corrosion cause the error in downhole engineering. After the system goes drift, it cannot collect the real-time down-hole engineering parameters. And this may lead to some serious down-hole accident such as sticking of tool and the drill pipe fault and so on, making oil field suffer great economic losses and causing some worse influence in the process of drilling. So it's important for us to get reliable down-hole engineering parameters. Taking various factors into consideration, the main western countries such as the United States, Britain etc. have executed technology blockade to our country, which slows down the domestic research in this field. The poor down-hole engineering parameters make domestic oil drilling technology behind the western countries, which has hindered the development of China's oil industry seriously [3-5].

Currently we have not in China fully taken the down-hole engineering parameters measure while drilling system in hand; it still fails to achieve the popularization of scientific research products. And the measured parameters mainly are formation parameters, lack of drilling engineering parameters measurement technology.

Now it is common practice to store the measurement data into a chip and getting drilling data playback. In order to

\footnotetext{
*Address correspondence to this author at the Southwest Petroleum University, Chengdu, 610500, P.R. China; Tel: 13096317138; E-mail: huze@swpu.edu.cn
}

guide next step of construction and related research, the drawback is not real-time display of down-hole working conditions, as it cannot be timely prevent and promptly take effective measures to control and handle complicate downhole accidents. Along with the development of the reliable technology, and with the present situation of oil drilling industry in our country, it is of great importance to provide a high reliable detecting system for China's oil industry to develop a down-hole engineering parameters measurement of the drilling system.

\section{SYSTEM MODEL}

\subsection{The Framework Design of System}

Down-hole engineering parameters measurement of drilling system is considered as an intelligent system with a high reliability of the down-hole engineering parameter acquisition, storage, transmission and processing. Its main parts consist of circuit of MCU and PC.

The circuit of MCU can accomplish signal detection, signal conditioning, data acquisition and storage for down-hole engineering parameters. PC parts mainly complete data analysis and processing functions, the circuit of $\mathrm{MCU}$ and $\mathrm{PC}$ parts are connected through MWD tools. The two parts work together completing the whole function of down-hole engineering parameters measurement system while drilling. The design scheme of the system is shown in Fig. (1).

At the same time, any case of program fault, such as electricity off, battery used up, memory full or communication failures happens; drilling parameters measurement system will be automatically switch standby working state to continue working state, ensuring the reliability of the measure system. 


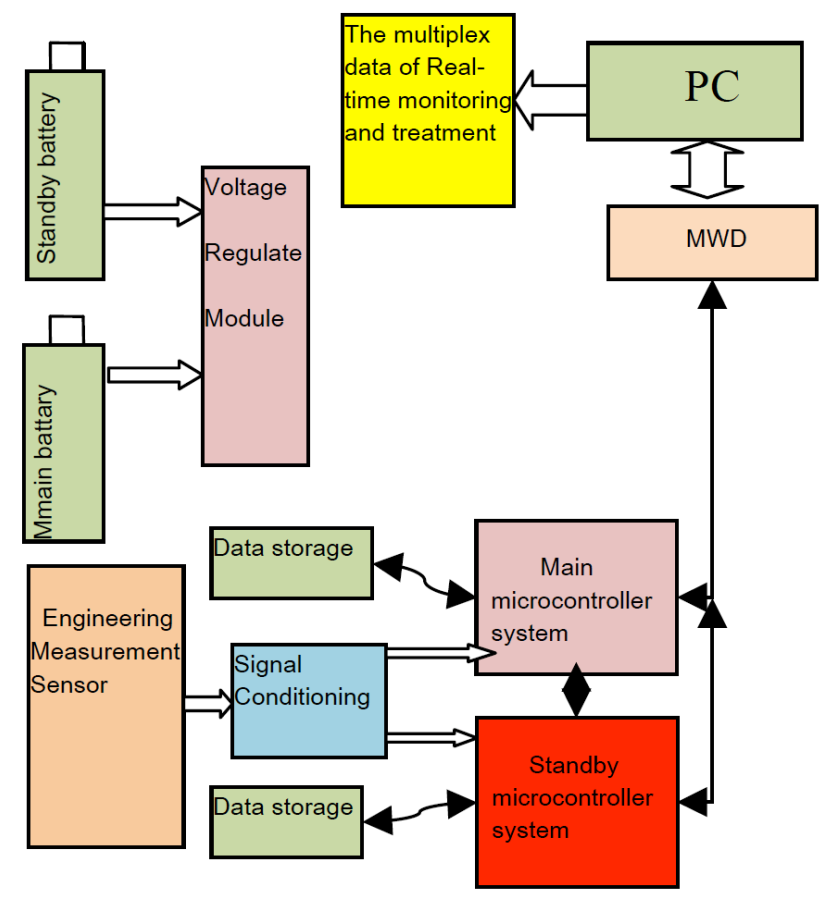

Fig. (1). Overall system design model.

\subsection{Technical Index}

The goal is to develop a set of drilling parameters of the measurement system, with which all the annular pressure, drilling pressure, temperature, torque and side pressure can be real-time monitored by drilling engineer who can understand and analysis the working condition of down-hole, and realize the optimization of drilling parameters [6-8]. It can set accurate data and scientific reference basis for the research of drilling and development through down-hole engineering parameters measurement system while drilling, so as to achieve the purpose of design and provide production guidance. The down-hole parameters with drilling tester is mainly responsible for the engineering parameters collection, data acquisition, data storage and data transmission, all of which are done on a circuit board. The circuit board is fixed in a short section of the slot, take the down-hole environment (including mechanical parts, electronic devices and sensors) into consideration, the design should meet the following conditions: $100 \mathrm{Mpa}$ for the highest voltage, $125^{\circ} \mathrm{C}$ for the highest temperature, $20 \mathrm{~g}$ for the greatest vibration; It also should meet the technical requirement for drilling pressure measurement range of $0-1000 \mathrm{kN}$; torque measurement range of $0-8 \mathrm{kN} * \mathrm{~m}$, temperature measurement's range of $0-125^{\circ} \mathrm{C}$, the annular pressure range of $0-100 \mathrm{Mpa}$, storage capacity for $32 \mathrm{MB}$, and the maximum working time is for $150 \mathrm{~h}$.

\subsection{Reliability Measurement}

For the downhole instrument, it always working under thousands of meters depth, so it has a very high requirements for instruments on reliability to cope with the severe environment such as high temperature, high pressure, strong vibration and strong corrosion etc, especially for those drilling parameters which can cause instrument vibration violent when it works, thus has higher requirement for the instruments to cope with violent vibration. Therefore, in the de- veloping process of designing the down-hole instrument, we must consider the problem of how to raise the reliability to guarantee the normal operation in such environment [9-12].

\subsubsection{Thermal Performance Design}

In the down-hole, and the temperature is the very main environmental factor to affect the reliability of the instrument when it works [13]. In order to improve the system's ability of withstanding high temperatures, we must try to reduce the heat dissipation of power consumption in the internal components, blocking the heat convection between the instruments and external environment, and putting some absorption materials to fill the instrument, and what's so on.

\subsubsection{Instrumental Vibration-proof Design}

Vibration and strike force the down-hole instrument to bear a very large mechanical force, and the mechanical forces will make element structure damaged, the device pins loosening, and device property will be worse and components parameters will be changed. So in order to improve the system's vibration resistance, full patch components are used when designed. And we put some anti-vibration rubber in the components and put the circuit board in the slot which is full of silica gel [14].

\subsubsection{Double System Design}

To realize the drilling engineering parameters double measurement system, we must ensure the redundant function according to down-hole engineering parameters measurement while drilling system, so that different redundant ways can get the reasonable application. Hardware redundancy, Information redundancy, time redundancy, or software redundancy will never mutually exclusive. During the designing process of the drilling engineering parameters double measurement system, these four redundant technologies need to be applied.

\subsection{Down-hole Instrument Design Scheme}

For the down-hole instrument, the design should use the parts with a simple function as far as possible, minimize the number of parts, and make use of standardized unit circuit or mature circuit to finalize the design. The design, in addition to the need to meet the most basic functions, but also must pay attention to the following requirements:

\subsubsection{The Strong Environmental Adaptability}

Down-hole instrument are working in the harsh downhole environment, so down-hole instrument must be able to meet the requirements of the harsh environment, this only way can guarantee the down-hole instrument to have a longterm reliable and stable work.

\subsubsection{Application of the Modular Design.}

The down-hole instrument should divide the whole into many function modules, due to the modular design, the down-hole instrument has easy to replace, fault isolation, easy maintenance and function scattered, etc.

\subsubsection{Convenient Operation and Maintenance}

The operation convenient is mainly manifested in intuitive operation, simple, image, and is convenient for the user 
to master; the maintenance convenient mainly displays in that fault is easy to find and exclude, when instrument appears.

\subsubsection{Good Real-time Performance}

When interior and exterior events happened, Good realtime performance manifests the down-hole instrument can be able to respond quickly, and carry on the corresponding operation, making information not lost, also not to delay the operation.

\section{THE CIRCUIT DESIGN OF HARDWARE}

\subsection{The Design of Sensor and Signal Conditioning Cir- cuit}

Because the sensors work in the severe environment with thousands of meters depth, so they used in this design need to pass strict selection in the measuring range, sensor size, sensor measurement method and signal output method. For the measurement of annular pressure, it chosen CYB-15S high temperature and pressure sensors, and use full-bridge strain to test the drilling pressure, torque and lateral force measurement.

Sensor will convert the 4-channel signal (annular pressure, drilling pressure, torque, side pressure) to current. Since the sensor output signal is so weak that sensor output signals should be filtered and amplified by an instrumentation amplifier through the signal processing circuit. This design choose AD8552 operational amplifier as the core device, and it provides a good choice for low frequency microvolt signal detection for its advantages in low noise, zero drift, single power supply and high input resistance (Fig. 2).

\subsection{Data Acquisition and Storage Circuit}

Data acquisition and storage module's main function is to convent 4 channel project signal. And put the store data into the data storage. To save space, we choose the Infineon's $\mathrm{XC} 886$ which has 8-channel $\mathrm{AD}$, the conversion time is 1.5 us with a resolution of 10 . Data storage using the nonvolatile FLASH storage AT45DB321D, The amount of memory available is $32 \mathrm{MB}$, and using SPI serial interface to communicate with XC886 (Fig. 3).

\subsection{Data Transmission Circuit}

In order to realize communication, down-hole engineering parameters measurement while drilling system applies serial interface communication circuit to transmit engineering parameters data to MWD, and the serial communications chip used is MAX3222. Once the single chip computer addressed, the single chip computer will transfer the relevant engineering parameters data according to the requirements of computer. MWD and engineering short are connected by double connection, the subordinate computer should not occupy sending bus unless accepting the mainframe's command, when the subordinate computer accepts the mainframe's data orders, the subordinate computer must return the data to the mainframe through the bus (Fig. 4).

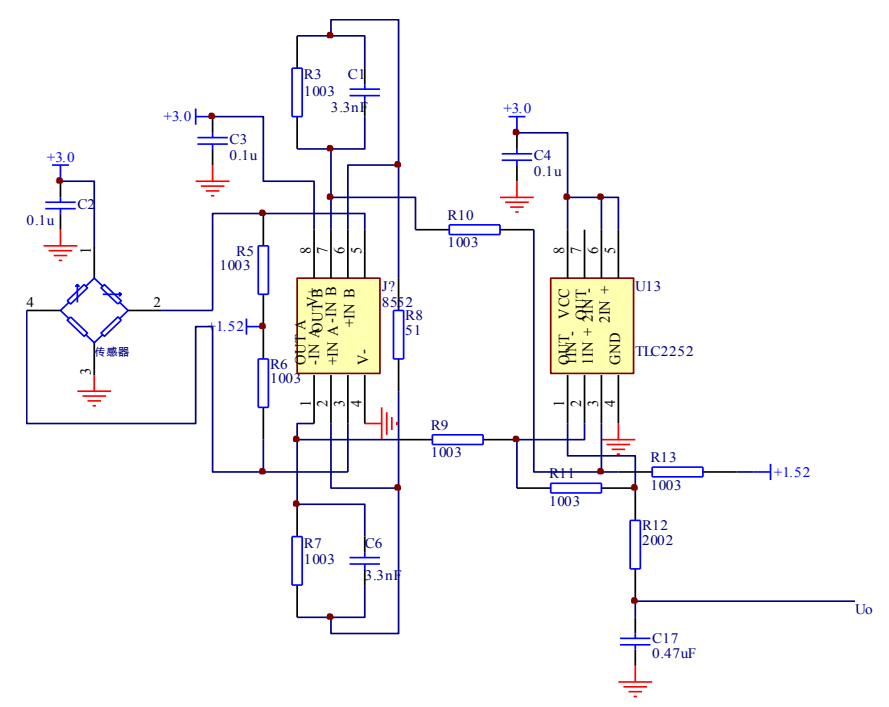

Fig. (2). Signal Conditioning circuit.

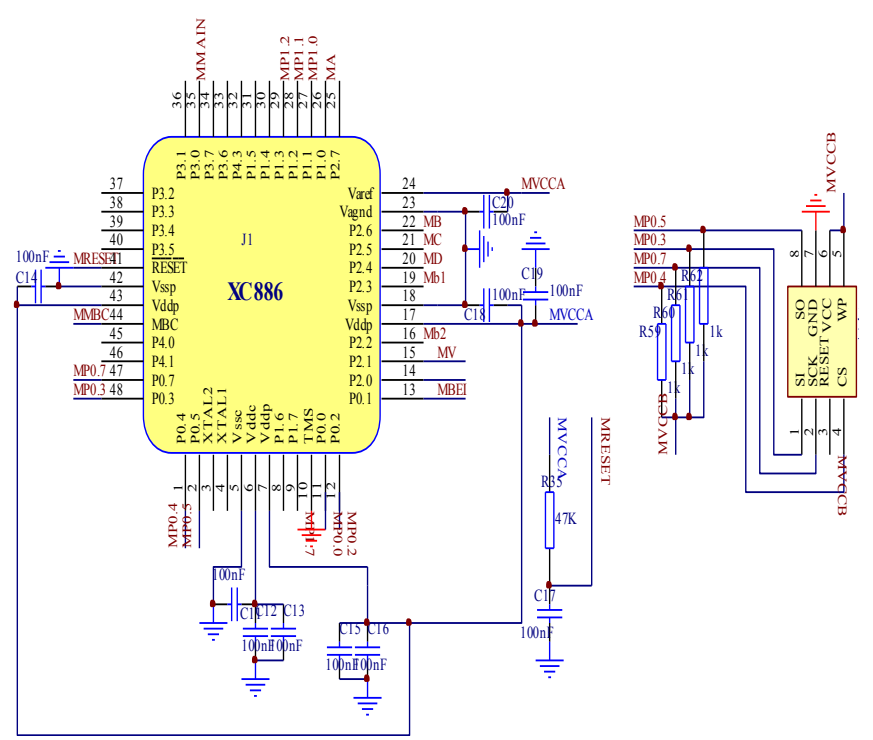

Fig. (3). Data acquisition and storage interface circuit.

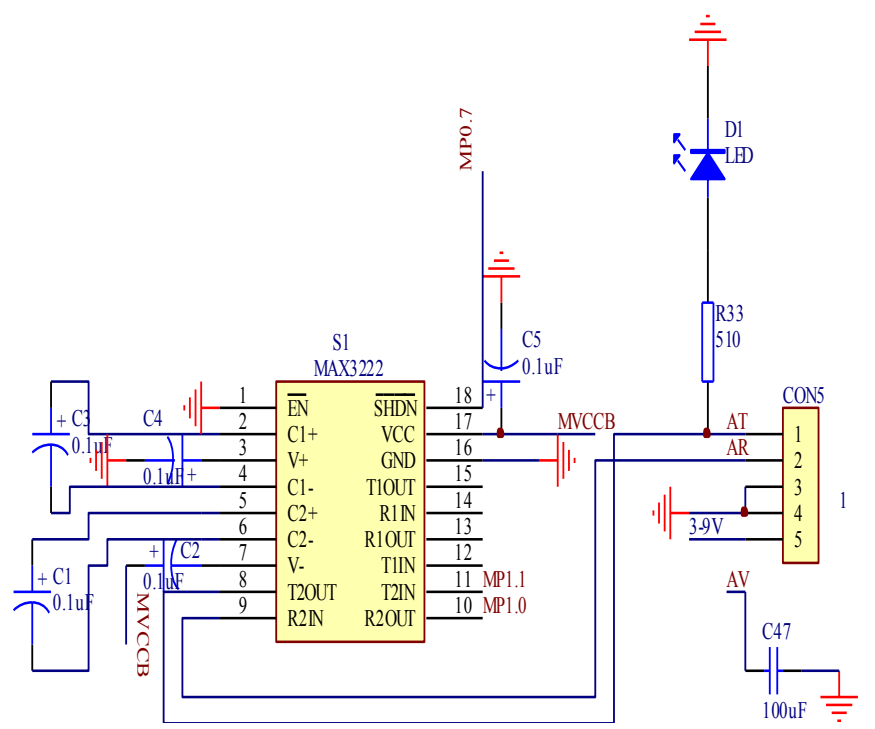

Fig. (4). Data transmission circuit. 


\subsection{Power Circuit}

With the characteristics of high energy density ,long life ,low self-discharge, pollution-free, the lithium ion battery become the mainstream product in battery market quickly. So we choose lithium battery in our system. Taking the system working environment into consideration, the system will use tailored high temperature lithium battery, for cylindrical shape, size $\varphi 35 \times 60 \mathrm{~mm}$, battery capacity of $30 \mathrm{Ah}$, the working temperature is ranged $-40{ }^{\circ} \mathrm{C}$ to $+175^{\circ} \mathrm{C}$ as shown in Fig. (5).

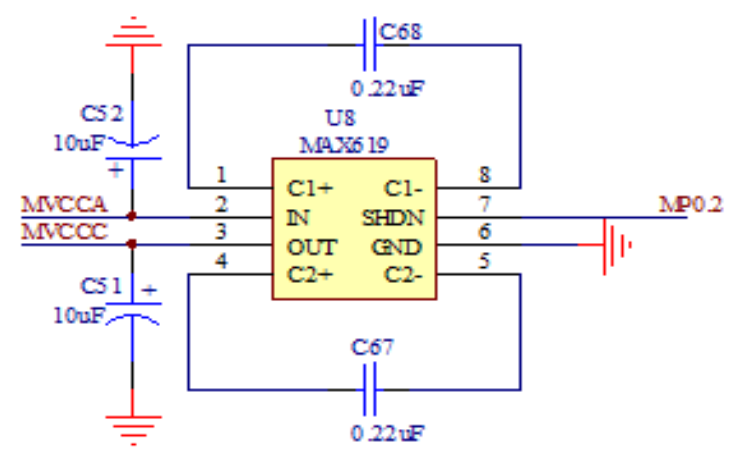

Fig. (5). 5V Power circuit.

The power supply system was divided into $5 \mathrm{~V}$ power supply and $3.3 \mathrm{~V}$. For the voltage applied on the temperature sensor is $5 \mathrm{~V}$, we use chip MAX619ESA to switch $3.6 \mathrm{~V}$ to $5 \mathrm{~V}$ and use chip TPS7233Q to switch $3.6 \mathrm{~V}$ to $3.3 \mathrm{~V}$.and use the single chip microcomputer to control the supply of $5 \mathrm{~V}$ direct-current power and $3.3 \mathrm{~V}$ amplifier circuit as shown in Fig. (6).

\section{SOFTWARE DESIGN OF THE SYSTEM}

Software design of the system is divided into two parts: the software design of test system and the software design of computer processing. The software of test system mainly realizes the single chip microcomputer's data collection, storage and transmission control. And the program is divided into 2 parts: the program of main microcontroller system and the program of standby microcontroller system. the main program of system flow as shown in Fig. (7). The software of computer processing mainly uses LabVIEW to read, analysis and display data as well as other functions.

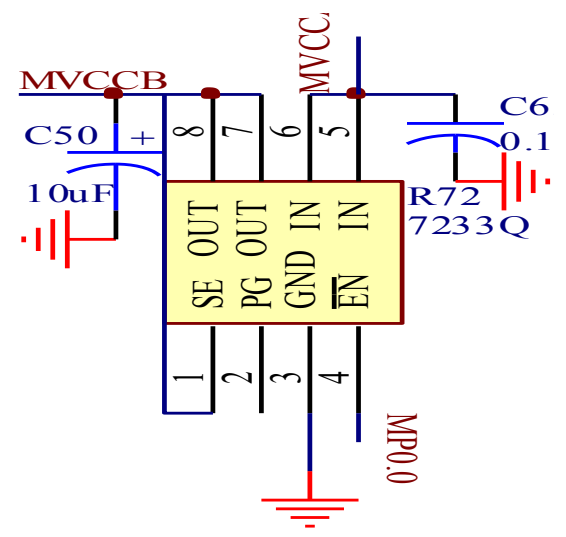

\section{SYSTEM TESTING}

In order to guarantee the normal work of test system, we must test and debug the hardware and software in course of their development. After we complete debugging, we need test the system through laboratory testing, high temperature test, vibration test and field test [12-14].

Fig. (7) shows the contrast of the instrumental record WOB data and logging record WOB data. The instrument can clearly record the WOB near the drill bit, and working conditions can be seen very much in line with the comparison of the ground logging record. meanwhile, the tool from the analysis point of view to meet the working conditions of the actual drilling, and can clearly see the near-bit, which provides a very intuitive as a means for our analysis of the practical work of the down-hole drill bit.

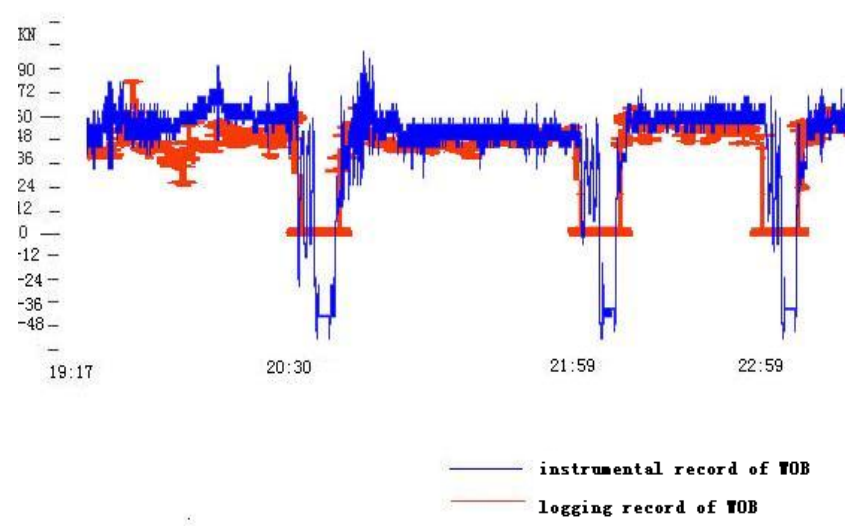

Fig. (7). The contrast of the instrumental record WOB data and logging record WOB data.

\section{CONCLUSION}

This paper puts forward a kind of design scheme of down-hole engineering parameters measurement system while drilling. From the hardware design and software design it elaborates the development process of underground engineering parameters with drilling test system in detail; the following achievements have been obtained through this research.

Chip XC886 as a core of controlling and operation has been applied to realize the hardware circuit design of downhole engineering parameters measurement system while drilling, and the engineering parameters signal disposal, signal acquisition storage and signal transmission.

With the reliable technology and double engineering parameters test system, drilling parameters measurement system will be automatically switch to standby working state to continue working. Any cases of program fault above happens, such as electricity off, battery used up, memory full or communication failures etc.

After the in-site test, down-hole engineering data has been collected. Down-hole engineering measuring instrument runs well and it can meet the application requirements of the drilling field.

Fig. (6). 3.3V Power circuit. 


\section{CONFLICT OF INTEREST}

The authors confirm that this article content has no conflict of interest.

\section{ACKNOWLEDGEMENTS}

This work is Supported by scientific research starting project of SWPU (No. 2014QHZ029), national natural science foundation of China (No. 51504211) the State administration of national security (No.sichuan-009-2013AQ, No. sichuang-0021-2014AQ), and the Sichuan educational committee (No. 15ZB0060).

\section{REFERENCES}

[1] B. Smith "International field-wide deployment of in-well optical flow-meters and pressure/temperature gauges at buzzard field", Intelligent Energy Conference and Exhibition, 2008.

[2] X.W. Lv, A.Z. Li, and W. Zhang, "Design of data acquisition controller in MWD testing system", Well Logging Technology, vol. 33, pp. 87-89, 2009.

[3] Valvano, Ahmad,Nayak, "Real time data acquisition and control”, ASEE Austin, 1999.

[4] C. Gary, F. Egil, C. Stewart, S. Bob, and F. Keith, "Fiber optic monitoring in openhole gravel pack completions", SPE Annual Technical Conference and Exhibition, 2002.
[5] L. Ge, Z. Hu, and Y.J. Fu, "The design of storable multiparameter logging system", Transducer and Microsystem Technologies, vol. 30, pp. 150-151, 2011.

[6] G. Heisig, B.H. Inteq, J.S. Eif, Exploration, and J.D. Macpherson, "Down-hole diagnosis of drilling dynamics data provides new level drilling process control to driller", SPE Annual Technical Conference and Exhibition, 1998.

[7] Leseultre and E. Lamine, Security DBS and A.Jonsson, Saga Petroleum ASA, "An Instrumented Bit: A necessary step to the intelligent BHA", IADC/SPE Drilling Conference, 1998.

[8] G. Lou, W. Li, and X.B. Deng, "Designing of small-signal amplifing circuit", Journal of Zhejiang Sci-Tech University, pp. 6164, 2007.

[9] M. HutchinSon, Anadrill, L. Remzer-Cooper, Sculmberger, S.P.E. Merbers, "Using down-hole annular pressure measurements to anticipate drilling problems", SPE Annual Technical Conference and Exhibition, 1998.

[10] B. Sandøy, Improved reservoir management with intelligent multi-zone WAG injectors and down-hole optical flow monitoring. SPE Production \& Operations, vol. 25, no. 2, pp. 178-189, 2007.

[11] Vos Bart E. "The benefits of monitoring torque and drag in real time", IADC/SPE Asia Pacific Drilling Technology, 2000.

[12] L. Ge, F. Su, Z. Hu, Q. LI, and R. Chen, "Research on power line carrier technology for the intelligent drill pipe", Advances in Information Sciences and Service Sciences, vol. 5, 2013.

[13] J. T. Finger, and A. J. Mansure, "Development of a system for diagnostic while drilling”, SPE/IADC Drilling Conference, 2003.

[14] G. Heising, "Down-hole diagnosis of drilling dynamics data provids new level drilling process", Journal of Petroleum Technology, vol. 5, pp. 38-39, 1999.

Received: July 6, 2014

Revised: October 8, 2014

Accepted: December 8, 2014

(C) Ze et al.; Licensee Bentham Open.

This is an open access article licensed under the terms of the (https://creativecommons.org/licenses/by/4.0/legalcode), which permits unrestricted, noncommercial use, distribution and reproduction in any medium, provided the work is properly cited. 